\title{
DIFFERENCE OF CD ENRICHMENT AND TRANSPORT IN ALFALFA (MEDICAGO SATIVA L.) AND INDIAN MUSTARD (BRASSICA JUNCEA L.) AND CD CHEMICAL FORMS IN SOIL
}

\author{
He, Z. ${ }^{\#}$ - HuANG, C. ${ }^{\#}-$ Xu, W. ${ }^{*}$ - Chen, Y. - ChI, S. - ZhANG, C. - LI, Y. - LI, T. - YANG, M. - \\ FENG, D. - CHI, Y. \\ College of Resources and Environmental Sciences, Southwest University \\ 400715 Chongqing, P. R. China \\ ${ }^{\#}$ Authors He and Huang should be as co-first authors \\ *Corresponding author \\ e-mail:xuwei_hong@163.com \\ (Received $7^{\text {th }}$ Feb 2018; accepted $3^{\text {rd }}$ May 2018)
}

\begin{abstract}
In order to compare the application potential of alfalfa (Medicago sativa L.) and Indian mustard (Brassica juncea L.) on cadmium contaminated soil, difference in dry weight, $\mathrm{Cd}$ content and accumulation, transport and enrichment coefficient between alfalfa and Indian mustard were studied under different $\mathrm{Cd}$ levels $\left(0,75,150,300\right.$ and $\left.600 \mathrm{mg} \cdot \mathrm{kg}^{-1}\right)$ using soil culture test. Also, Cd forms in soil were analyzed. The results showed that the dry weight of shoots and roots of alfalfa and Indian mustard decreased significantly $(P<0.05)$ with the increase of soil Cd levels, decreasing by $50.00-71.90 \%$ and $29.60-59.30 \%$ (alfalfa), 59.60-89.00\% and 64.30-74.80\% (Indian mustard) compared with the control. With the increase of soil Cd level, Cd concentration and $\mathrm{Cd}$ accumulation in shoots and roots of alfalfa and Indian mustard increased significantly $(P<0.05)$. At same soil $\mathrm{Cd}$ level, $\mathrm{Cd}$ concentration in shoots and roots was in order of alfalfa > Indian mustard, while Cd accumulation was in order of Indian mustard $>$ alfalfa. At the soil Cd level of $75 \mathrm{mg} \cdot \mathrm{kg}^{-1}, \mathrm{Cd}$ concentration in shoots of alfalfa and Indian mustard exceeded the critical value of Cd hyperaccumulator $\left(100 \mathrm{mg} \cdot \mathrm{kg}^{-1}\right), 356.463 \mathrm{mg} \cdot \mathrm{kg}^{-1}$ and $308.735 \mathrm{mg} \cdot \mathrm{kg}^{-1}$ respectively. The enrichment coefficient (BCF) of alfalfa and Indian mustard was above 1 under all $\mathrm{Cd}$ levels, and the transport coefficient (TF) and BCF was in order of Indian mustard > alfalfa. Based on comprehensive consideration of biomass, $\mathrm{Cd}$ accumulation, transport coefficient and enrichment coefficient, Indian mustard is more suitable as repair material for soil Cd pollution.
\end{abstract}

Keywords: soil Cd pollution, Cd hyperaccumulator, transfer coefficient, enrichment coefficient, soil Cd forms

\section{Introduction}

Cadmium (Cd) is the top soil heavy metal pollutant. According to statistics, about 30,000 tons of $\mathrm{Cd}$ is released into the environment each year in the world, and of which $\mathrm{Cd}$ released into the soils reaches about 82-94\% (Xiong et al., 2015). The total amount of $\mathrm{Cd}$ emitted into the environment from industrial waste is 680 tons per year in China (Ning et al., 2015). Cadmium pollution in farmland is $280,000 \mathrm{hm}^{2}$, and annual output of agricultural products with excessive $\mathrm{Cd}$ is nearly 1.5 million tons in China (Li et al., 2017b; Liu et al., 2017). Cadmium can be absorbed by plants and can be enriched in the human body through the food chain, endangering human health. Therefore, soil $\mathrm{Cd}$ pollution control and remediation has drawn wide attention from researchers (Li et al., 2017b; Marzban et al., 2017).

Indian mustard (Brassica juncea L.) is cruciferous Brassica with short growth cycle and great aboveground biomass. Capable of enriching a variety of heavy metals. When Cd was added at $0-200 \mathrm{mg} \cdot \mathrm{kg}^{-1}$, the biomass of Indian mustard was unaffected, and 
shoot $\mathrm{Cd}$ concentration was up to $7.824-102.672 \mathrm{mg} \cdot \mathrm{kg}^{-1}$, and root Cd concentration was up to $0.374-191.910 \mathrm{mg} \cdot \mathrm{kg}^{-1}$ (Yang et al., 2011). Alfalfa (Medicago sativa L.) a leguminous perennial herb, is a high-yielding cash crop. Sun and Song (2015) reported that $\mathrm{Cd}$ concentration below $25 \mathrm{mg} \cdot \mathrm{kg}^{-1}$ can promote the growth of alfalfa shoot and root. With the increase of $\mathrm{Cd}$ level in soil, Cd concentrations in alfalfa shoot and root increase, and also has a higher enrichment effect on Cd ions. At present, there is little research on comparison of $\mathrm{Cd}$ uptake by alfalfa and Indian mustard. Therefore, in this study, the differences in biomass, Cd concentration and accumulation in alfalfa and Indian mustard, as well as $\mathrm{Cd}$ forms in soil were studied using soil culture test with different $\mathrm{Cd}$ concentrations, and plant suitable for soil $\mathrm{Cd}$ pollution remediation was screened out.

\section{Materials and methods}

\section{Plant material, soil and Cd treatments}

The seeds of alfalfa (Medicago sativa L.) were purchased from Jiangxi Scarecrow Agricultural Park, and the seeds of Indian mustard (Brassica juncea L.) were purchased from Angoo Plant Science and Technology, China. The soil was collected from the purple soil base of Southwest University in Beibei District of Chongqing, China. The soil $\mathrm{pH}$ was 5.23 , the content of organic matter was $8.87 \mathrm{~g} \cdot \mathrm{kg}^{-1}$, that of available phosphorus was $38.59 \mathrm{mg} \cdot \mathrm{kg}^{-1}$, that of available potassium was $65.07 \mathrm{mg} \cdot \mathrm{kg}^{-1}$, that of total nitrogen was $1.54 \mathrm{~g} \cdot \mathrm{kg}^{-1}$, that of available nitrogen was $74.60 \mathrm{mg} \cdot \mathrm{kg}^{-1}$, that of total Cd was $0.110 \mathrm{mg} \cdot \mathrm{kg}^{-1}$, and that of available $\mathrm{Cd}<0.005 \mathrm{mg} \cdot \mathrm{kg}^{-1}$.

The soil culture experiment was conducted in the glass greenhouse of College of Resources and Environment of Southwest University, China from March to May in 2015. An opaque black plastic basin $(25 \mathrm{~cm}$ in diameter and $17 \mathrm{~cm}$ in height) was used in the experiment. The $5 \mathrm{~kg}$ of air-dried soil screened by $5 \mathrm{~mm}$ sieve was loaded in each basin. The $\mathrm{CdCl}_{2} \cdot 2.5 \mathrm{H}_{2} \mathrm{O}$ solution was added to the soil and mixed well. The soil $\mathrm{Cd}^{2+}$ pollution levels were simulated at $0,75,150,300$ and $600 \mathrm{mg} \cdot \mathrm{kg}^{-1}$, and kept balance for two weeks. The seedlings of Indian mustard and alfalfa with $5 \mathrm{~cm}$ high were then transplanted 6 and 10 plants for each pot. The moisture content in soil was kept 70-75\% of the maximum moisture in the fields with deionized water. Fast- measurement of Soil Moisture (TZS-IW, Zhejiang Tuopu Instrument Co., Ltd., China) was used to determine the moisture content in soil. In the basic fertilizer the used amount of $\mathrm{P}\left(\mathrm{NH}_{4} \mathrm{H}_{2} \mathrm{PO}_{4}\right)$ and $\mathrm{K}(\mathrm{KCl})$ were 100 and $150 \mathrm{mg} \cdot \mathrm{L}^{-1}$ respectively and Nitrogen content $\left(\mathrm{NH}_{4} \mathrm{H}_{2} \mathrm{PO}_{4}\right.$ and urea) was $180 \mathrm{mg} \cdot \mathrm{L}^{-1}$. $\mathrm{N}$ fertilizer was applied in three installments: $40 \%$ for basal and $60 \%$ each for seedling stages which applied with 15 days' interval after transplanting, each time 30\%. All experiments were performed in triplicate and arranged at random. After 60 days, 6 (Indian mustard) and 10 (alfalfa) plants for each pot were harvested, and were separated into shoots and roots, washed free of soil with tap water and then rinsed with $0.1 \mathrm{M} \mathrm{HCl}$ followed by several rinses with deionized water (Kachenko and Singh, 2006). The harvested plants were oven-dried at $105^{\circ} \mathrm{C}$ for $15 \mathrm{~min}$, and oven drying to constant weight in $60^{\circ} \mathrm{C}$.

\section{Analysis of soil physicochemical properties}

The soil $\mathrm{pH}$ was ascertained in 1:5 (soil:water), and available phosphorus, available potassium and total nitrogen in soil was determined in term of a previously report 
(Rayment and Higginson, 1992). The soil organic matter content was determined on the basis of a previously published method (McCleod, 1975).

\section{Analysis of Cd concentration in soil and plants}

Soil containing $\mathrm{Cd}$ was first boiled with $\mathrm{HNO}_{3}-\mathrm{HClO}_{4}(v: v=4: 1)$, and its concentration was determined using an atomic absorption spectrophotometer (SIMMA 6000; PerkinElmer, Norwalk, CT, USA). The plant samples were first air-dried and ground and the $\mathrm{Cd}$ concentration in the plants was determined using a similar method to that used to quantify the levels of $\mathrm{Cd}$ in the soil. The results were monitored for quality control in following with plant standard reference material (GBW08513) and soil (GBW08303) obtained from the National Institute of Standards and Technology, China. The recovery rates of all the plants and soils were higher than $95 \%$, and the relative standard deviation (RSD) for the precision of the tests was less than $10 \%$.

1. Transport coefficient $(\mathrm{TF})=\mathrm{Cd}$ concentration in shoot $\left(\mathrm{mg} \cdot \mathrm{kg}^{-1}\right) / \mathrm{Cd}$ concentration in root $\left(\mathrm{mg} \cdot \mathrm{kg}^{-1}\right)$ (Sun et al., 2016).

2. Enrichment coefficient $(\mathrm{BCF})=\mathrm{Cd}$ concentration in shoot (root) $\left(\mathrm{mg} \cdot \mathrm{kg}^{-1}\right) /$ soil Cd $\left(\mathrm{mg} \cdot \mathrm{kg}^{-1}\right)$ (Feng et al., 2016).

\section{Soil Cd form determination}

Method proposed by Tessier et al. (1979) was used to extract Cd from soil. The Cd concentration of each form was determined by atomic absorption spectrophotometry (Perkin Elmer SIMMA 6000, Norwalk, USA). The detection limit of atomic absorption spectrophotometer was $0.005 \mathrm{mg} \cdot \mathrm{kg}^{-1}$. Soil standard substance (GBW \# 08303) from the National Institute of Standards and Technology was used to monitor the quality of the results. The Cd recovery of all soil samples was higher than $95 \%$, and the accuracy of relative standard deviation (RSD) was within $10 \%$.

\section{Statistical analysis}

Three-way analysis of univariate ANOVA and correlation analysis were performed using SPSS version 21.0 package (SPSS, 2009). The variables analyzed separately were $\mathrm{Cd}$ concentration and $\mathrm{Cd}$ accumulation in alfalfa and Indian mustard, and $\mathrm{Cd}$ chemical forms in soil. The level of significance was 0.05 .

\section{Results}

\section{Biomass}

As shown in Table 1, with the increase of soil Cd level, shoot and root dry weight of alfalfa and Indian mustard decreased significantly $(P<0.05)$, decreasing by 50.00 $71.90 \%$ and 29.60-59.30\% (alfalfa), 59.60-89.00\% and 64.30-74.80\% (Indian mustard) respectively. At same soil Cd levels, biomass of Indian mustard shoot and root was significantly higher than that of alfalfa. The tolerance coefficients of alfalfa shoot and root were $28.21-50.00 \%$ and $40.74-70.37 \%$ when exposed to $\mathrm{Cd}$, respectively. When the Cd pollution level was above $150 \mathrm{mg} \cdot \mathrm{kg}^{-1}$, the tolerance coefficients of each part were lower than $50 \%$. The tolerance coefficients of Indian mustard shoot and root were $10.97-40.37 \%$ and $25.22-35.65 \%$ when exposed to $\mathrm{Cd}$, respectively, both lower than $50 \%$. 
Table 1. Dry weights and resistance coefficient of two plants in different soil Cd levels

\begin{tabular}{c|c|c|c|c|c|c|c|c}
\hline \multirow{2}{*}{$\begin{array}{c}\text { Soil Cd } \\
\text { levels } \\
\left(\mathbf{m g} \cdot \mathbf{k g}^{-\mathbf{1}}\right)\end{array}$} & \multicolumn{4}{|c|}{ Dry weight $\left(\mathbf{g} \cdot \mathbf{p l a n t}^{\mathbf{- 1}}\right)$} & \multicolumn{3}{c}{ Resistance coefficient (\%) } \\
\cline { 2 - 9 } & Alfalfa & $\begin{array}{c}\text { Indian } \\
\text { mustard }\end{array}$ & Alfalfa & $\begin{array}{c}\text { Indian } \\
\text { mustard }\end{array}$ & Alfalfa & $\begin{array}{c}\text { Indian } \\
\text { mustard }\end{array}$ & Alfalfa & $\begin{array}{c}\text { Indian } \\
\text { mustard }\end{array}$ \\
\hline 0 & $0.078 \pm 0.007 \mathrm{a}$ & $0.857 \pm 0.033 \mathrm{a}$ & $0.027 \pm 0.002$ & $0.115 \pm 0.013 \mathrm{a}$ & - & - & - & - \\
75 & $0.039 \pm 0.008 \mathrm{a}$ & $0.346 \pm 0.041 \mathrm{a}$ & $0.019 \pm 0.001 \mathrm{~b}$ & $0.041 \pm 0.001 \mathrm{a}$ & 50.00 & 40.37 & 70.37 & 35.65 \\
150 & $0.023 \pm 0.003 \mathrm{~b}$ & $0.157 \pm 0.020 \mathrm{a}$ & $0.013 \pm 0.002 \mathrm{~b}$ & $0.032 \pm 0.003 \mathrm{a}$ & 29.49 & 18.32 & 48.15 & 27.83 \\
300 & $0.022 \pm 0.001 \mathrm{~b}$ & $0.140 \pm 0.013 \mathrm{a}$ & $0.013 \pm 0.002 \mathrm{~b}$ & $0.030 \pm 0.002 \mathrm{a}$ & 28.21 & 16.34 & 48.15 & 26.09 \\
600 & $0.022 \pm 0.001 \mathrm{~b}$ & $0.094 \pm 0.017 \mathrm{a}$ & $0.011 \pm 0.001 \mathrm{~b}$ & $0.029 \pm 0.001 \mathrm{a}$ & 28.21 & 10.97 & 40.74 & 25.22 \\
\hline
\end{tabular}

Note: tolerance coefficient $=\mathrm{Cd}$ treatment plant biomass $/$ control plant biomass $\times 100$. The results listed are mean \pm standard deviation. Different lowercase letters indicate the difference between different plants under the same $\mathrm{Cd}$ level $(\mathrm{P}<0.05)$. The same below

\section{Cd concentration in shoot and root}

As shown in Figure 1, with the increase of soil $\mathrm{Cd}$ level, the $\mathrm{Cd}$ concentrations in shoots and roots of the two plants increased significantly $(P<0.05)$.

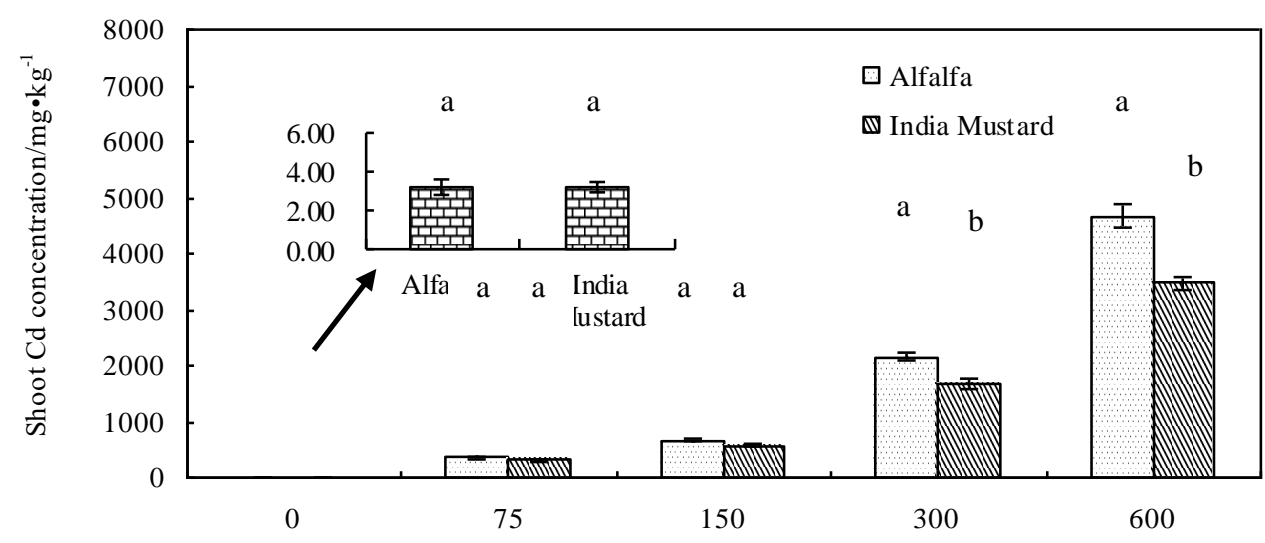

Soil Cd level $/{\mathrm{mg} \cdot \mathrm{kg}^{-1}}^{-1}$

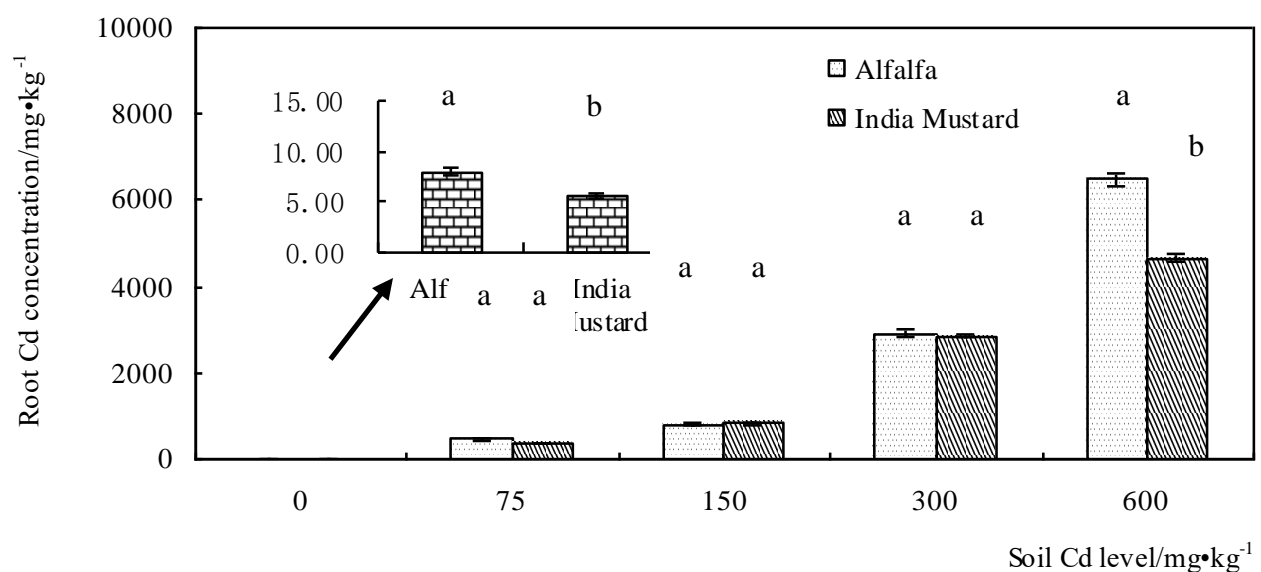

Figure 1. Effect of different soil Cd levels on Cd concentration of shoots and roots in two plants. Note: Different lowercase letters indicate the difference between different plants under the same Cd pollution level $(P<0.05)$. The same below 
Under the same Cd level, the Cd concentration in roots of the two plants was higher than that in shoots, and $\mathrm{Cd}$ concentrations in shoot and root were in order of alfalfa > Indian mustard. At $75 \mathrm{mg} \cdot \mathrm{kg}^{-1}$ soil Cd level, shoot $\mathrm{Cd}$ concentrations in alfalfa and Indian mustard passed the critical level of Cd hyperaccumulator $\left(100 \mathrm{mg} \cdot \mathrm{kg}^{-1}\right)$ which were $356.463 \mathrm{mg} \cdot \mathrm{kg}^{-1}$ and $308.735 \mathrm{mg} \cdot \mathrm{kg}^{-1}$ respectively.

\section{Cd accumulation in shoot and root}

As can be seen from Figure 2, with the increase of soil Cd levels, Cd accumulation in shoots and roots of the two plants increased with the increase of soil Cd level. At the $600 \mathrm{mg} \cdot \mathrm{kg}^{-1}$ soil $\mathrm{Cd}$ level, Cd accumulations of shoot and root in alfalfa and Indian mustard reach the peak by $175.540,101.632$ and $324.70 \mu \mathrm{g} \cdot$ plant $^{-1}$ respectively. Under the same Cd level in soil, Cd accumulations of shoot and root was in order of alfalfa < Indian mustard.
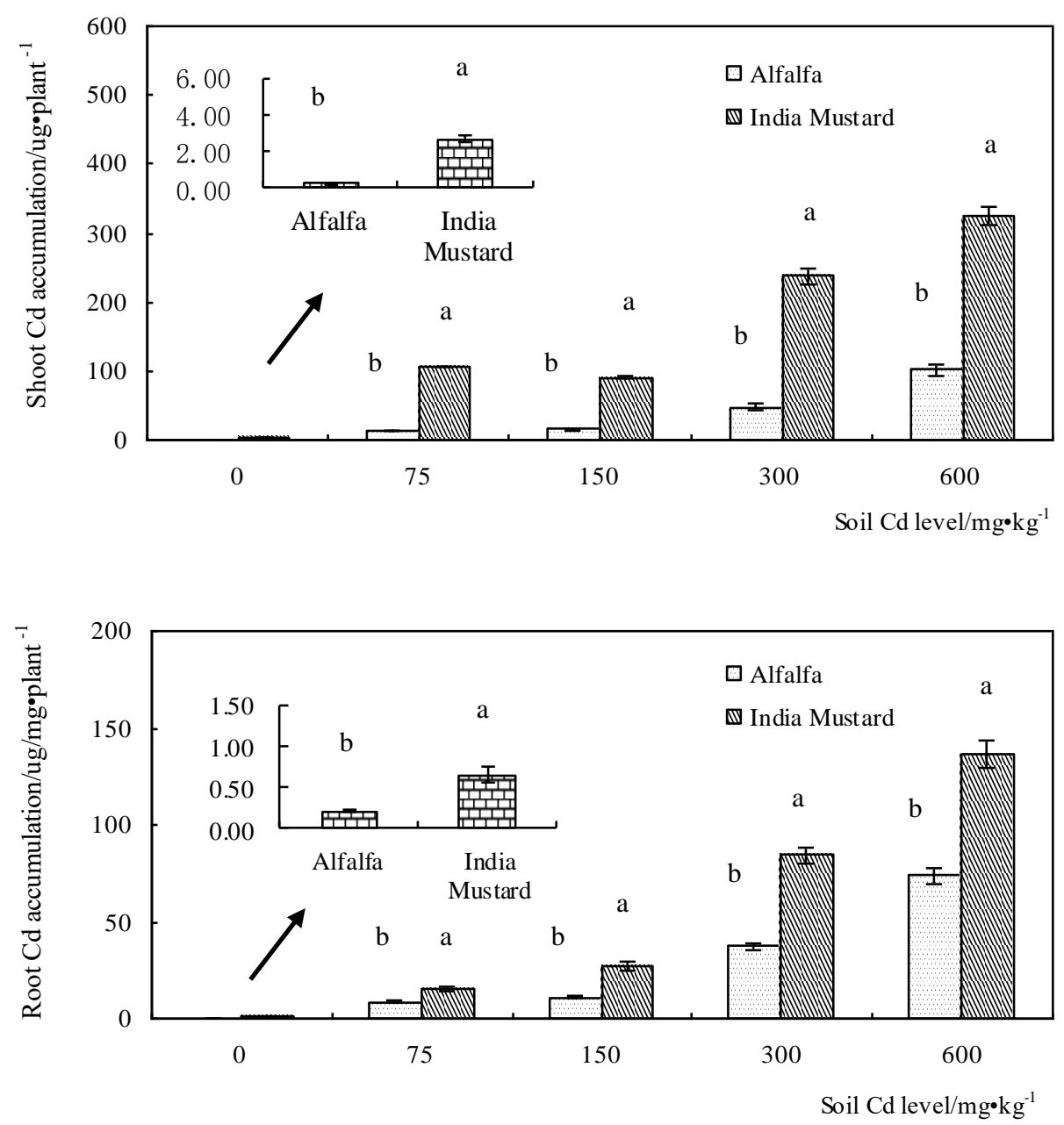

Figure 2. Effect of different soil Cd levels on Cd accumulation in two plants

\section{Comparison of enrichment and transport capacity}

As shown in Table 2, BCF of shoots of alfalfa and Indian mustard decreased firstly, reaching the lowest level at $150 \mathrm{mg} \cdot \mathrm{kg}^{-1} \mathrm{Cd}$ level, and then increased. Compared to that 
at $150 \mathrm{mg} \cdot \mathrm{kg}^{-1} \mathrm{Cd}$ level, the BCF of shoots of alfalfa and Indian mustard increases by $62.94 \%$ and $76.16 \%$ (alfalfa), $47.30 \%$ and $50.85 \%$ (Indian mustard) at the 300 and $600 \mathrm{mg} \cdot \mathrm{kg}^{-1} \mathrm{Cd}$ levels. With the increase of soil $\mathrm{Cd}$ level, the $\mathrm{BCF}_{\text {root/soil }}$ of alfalfa decreased first, reaching the lowest at $150 \mathrm{mg} \cdot \mathrm{kg}^{-1} \mathrm{Cd}$ level, down by $10.48 \%$ compared with that at $75 \mathrm{mg} \cdot \mathrm{kg}^{-1} \mathrm{Cd}$ level, and then increased. For Indian mustard, the $\mathrm{BCF}_{\text {root/soil }}$ first increased and then decreased, reaching the peak at $300 \mathrm{mg} \cdot \mathrm{kg}^{-1} \mathrm{Cd}$. The $\mathrm{BCF}$ of the two plants was above 1, with that of Indian mustard $>$ alfalfa. The TF of alfalfa and Indian mustard decreased with the increase of soil $\mathrm{Cd}$ levels, and the TF value was below 1. Under the same Cd levels, the TF was in order of Indian alfalfa > alfalfa.

Table 2. The values of BCF and TF in two plants

\begin{tabular}{c|c|c|c|c|c|c|c|c}
\hline $\begin{array}{c}\text { Soil Cd } \\
\text { levels } \\
\mathbf{m g} \cdot \mathbf{k g}^{-1}\end{array}$ & \multicolumn{2}{|c|}{ BCF $_{\text {Shoot/Soil }}$} & \multicolumn{2}{|c|}{ BCF $_{\text {Root/Soil }}$} & \multicolumn{2}{c|}{ BCF $_{\text {Plant/Soil }}$} & \multicolumn{2}{c}{ TF } \\
\hline 0 & - & $\begin{array}{c}\text { Indian } \\
\text { mustard }\end{array}$ & Alfalfa & $\begin{array}{c}\text { Indian } \\
\text { mustard }\end{array}$ & Alfalfa & $\begin{array}{c}\text { Indian } \\
\text { mustard }\end{array}$ & Alfalfa & $\begin{array}{c}\text { Indian } \\
\text { mustard }\end{array}$ \\
\hline 75 & $4.753 \pm 0.274 \mathrm{a}$ & $4.116 \pm 0.023 \mathrm{~b}$ & $6.042 \pm 0.278 \mathrm{a}$ & $4.917 \pm 0.163 \mathrm{~b}$ & $10.795 \pm 0.005 \mathrm{a}$ & $9.034 \pm 0.186 \mathrm{~b}$ & $0.789 \pm 0.082 \mathrm{~b}$ & $0.838 \pm 0.023 \mathrm{a}$ \\
150 & $4.421 \pm 0.159 \mathrm{a}$ & $3.837 \pm 0.068 \mathrm{~b}$ & $5.409 \pm 0.006 \mathrm{a}$ & $5.541 \pm 0.026 \mathrm{a}$ & $9.830 \pm 0.165 \mathrm{a}$ & $9.379 \pm 0.041 \mathrm{a}$ & $0.817 \pm 0.028 \mathrm{a}$ & $0.693 \pm 0.0150 \mathrm{~b}$ \\
300 & $7.204 \pm 0.052 \mathrm{a}$ & $5.652 \pm 0.305 \mathrm{~b}$ & $9.714 \pm 0.237 \mathrm{a}$ & $9.521 \pm 0.116 \mathrm{a}$ & $16.918 \pm 0.185 \mathrm{a}$ & $15.173 \pm 0.421 \mathrm{~b}$ & $0.742 \pm 0.023 \mathrm{a}$ & $0.593 \pm 0.025 \mathrm{~b}$ \\
600 & $7.788 \pm 0.200 \mathrm{a}$ & $5.788 \pm 0.219 \mathrm{~b}$ & $10.803 \pm 0.243 \mathrm{a}$ & $7.780 \pm 0.105 \mathrm{~b}$ & $18.591 \pm 0.443 \mathrm{a}$ & $13.568 \pm 0.324 \mathrm{~b}$ & $0.721 \pm 0.002 \mathrm{a}$ & $0.744 \pm 0.018 \mathrm{a}$ \\
\hline
\end{tabular}

Note: BCF (Enrichment coefficient) = Cd concentration in shoot (root) $\left(\mathrm{mg} \cdot \mathrm{kg}^{-1}\right) / \mathrm{soil} \mathrm{Cd}\left(\mathrm{mg} \cdot \mathrm{kg}^{-1}\right)$ (Feng et al., 2016); TF (Transport coefficient $)=\mathrm{Cd}$ concentration in shoot $\left(\mathrm{mg} \cdot \mathrm{kg}^{-1}\right) / \mathrm{Cd}$ concentration in root $\left(\mathrm{mg} \cdot \mathrm{kg}^{-1}\right)$ (Sun et al., 2016)

\section{Soil Cd chemical forms}

As shown in Table 3 and Figure 3, the Cd content in different forms of soil (EXC, $\mathrm{CAB}, \mathrm{FeMn}, \mathrm{OM}$ and RES) increased significantly with the increase of soil Cd level $(P<0.05)$. Cadmium fraction distribution coefficient (FDC) also demonstrated a corresponding trend. At the same $\mathrm{Cd}$ level, soil $\mathrm{Cd}$ of the two plants mainly exists as EXC-Cd. Cadmium fraction distribution coefficient (FDC) of EXC-Cd in soil of alfalfa and Indian mustard were $63.92-81.87 \%$ and $57.97-80.71 \%$ respectively. The OM-Cd content had the lowest distribution proportion under the same soil $\mathrm{Cd}$, with FDC at only $0.87-13.33 \%$. At the $300 \mathrm{mg} \cdot \mathrm{kg}^{-1}$ and $600 \mathrm{mg} \cdot \mathrm{kg}^{-1} \mathrm{Cd}$ levels, exchangeable Cd content in the soil planted with Indian mustard was significantly lower than that planted with alfalfa.

\section{Discussion}

Earlier reports suggested that $\mathrm{Cd}$ had no significant effect on plant growth at a low Cd level (Liu et al., 2013; Yu et al., 2017) and even stimulated and promoted plant growth (Wei et al., 2004). In this experiment, the biomass of alfalfa was significantly lower than that of the control at the $75 \mathrm{mg} \cdot \mathrm{kg}^{-1} \mathrm{Cd}$ level, indicating that $75 \mathrm{mg} \cdot \mathrm{kg}^{-1} \mathrm{Cd}$ had a serious injury to alfalfa growth. The results are consistent with those of Lou et al. (2015). In this study, with the increase of soil Cd level. It may be probable that growth and development of plants were directly related to $\mathrm{Cd}$ level, soil physicochemical property, fertility and soil type, but the specific reason remains to be further studied. 
Table 3. Effect of different Cd levels on Cd chemical forms in soil

\begin{tabular}{|c|c|c|c|c|c|c|c|c|c|c|}
\hline \multirow{2}{*}{$\begin{array}{c}\text { Soil Cd } \\
\text { levels } \\
\left(\mathbf{m g} \cdot \mathbf{k g}^{-1}\right)\end{array}$} & \multicolumn{2}{|c|}{ EXC-Cd } & \multicolumn{2}{|c|}{ CAB-Cd } & \multicolumn{2}{|c|}{ FeMn-Cd } & \multicolumn{2}{|c|}{ OM-Cd } & \multicolumn{2}{|c|}{ RES-Cd } \\
\hline & Alfalfa & Indian mustard & Alfalfa & $\begin{array}{l}\text { Indian } \\
\text { mustard }\end{array}$ & Alfalfa & $\begin{array}{l}\text { Indian } \\
\text { mustard }\end{array}$ & Alfalfa & $\begin{array}{l}\text { Indian } \\
\text { mustard }\end{array}$ & Alfalfa & $\begin{array}{l}\text { Indian } \\
\text { mustard }\end{array}$ \\
\hline 0 & $<0.005$ & $<0.005$ & $<0.005$ & $<0.005$ & $<0.005$ & $<0.005$ & $<0.005$ & $<0.005$ & $<0.005$ & $<0.005$ \\
\hline 75 & $46.093 \pm 0.521 \mathrm{a}$ & $40.141 \pm 0.551 \mathrm{~b}$ & $9.093 \pm 0.834 \mathrm{a}$ & $10.437 \pm 2.011 \mathrm{a}$ & $8.694 \pm 0.328 b$ & $10.088 \pm 2.509 \mathrm{a}$ & $2.522 \pm 0.499 \mathrm{~b}$ & $5.540 \pm 1.491 \mathrm{a}$ & $5.708 \pm 0.667 \mathrm{a}$ & $3.033 \pm 0.308 \mathrm{~b}$ \\
\hline 150 & $95.442 \pm 0.090 \mathrm{a}$ & $66.357 \pm 1.262 b$ & $14.273 \pm 1.675 \mathrm{a}$ & $11.933 \pm 1.001 \mathrm{~b}$ & $10.879 \pm 0.840 \mathrm{a}$ & $10.586 \pm 1.999 a$ & $3.525 \pm 1.494 b$ & $8.288 \pm 1.247 \mathrm{ba}$ & $6.221 \pm 0.161 \mathrm{a}$ & $5.385 \pm 0.339 b$ \\
\hline 300 & $142.382 \pm 22.228 \mathrm{a}$ & $117.148 \pm 7.278 b$ & $20.886 \pm 0.359 \mathrm{a}$ & $19.150 \pm 0.242 \mathrm{a}$ & $14.508 \pm 1.807 \mathrm{a}$ & $8.578 \pm 0.003 \mathrm{~b}$ & $3.528 \pm 0.170 \mathrm{~b}$ & $12.283 \pm 0.758 \mathrm{a}$ & $7.702 \pm 0.654 \mathrm{a}$ & $7.890 \pm 0.167 \mathrm{a}$ \\
\hline 600 & $330.700 \pm 3.299 \mathrm{a}$ & $291.113 \pm 18.349 b$ & $37.603 \pm 0.311 \mathrm{a}$ & $36.098 \pm 0.705 \mathrm{a}$ & $19.884 \pm 0.488 \mathrm{a}$ & $15.802 \pm 3.222 b$ & $4.863 \pm 0.164$ & $7.776 \pm 2.234 \mathrm{a}$ & $10.892 \pm 0.160 \mathrm{a}$ & $9.888 \pm 0.178 \mathrm{a}$ \\
\hline
\end{tabular}

Note: EXC-Cd, CAB-Cd, FeMn-Cd, OM-Cd and RES-Cd indicate exchangeable Cd, carbonate-bound Cd, Fe-Mn oxides-bound Cd, Organic Cd and residuals Cd, respectively

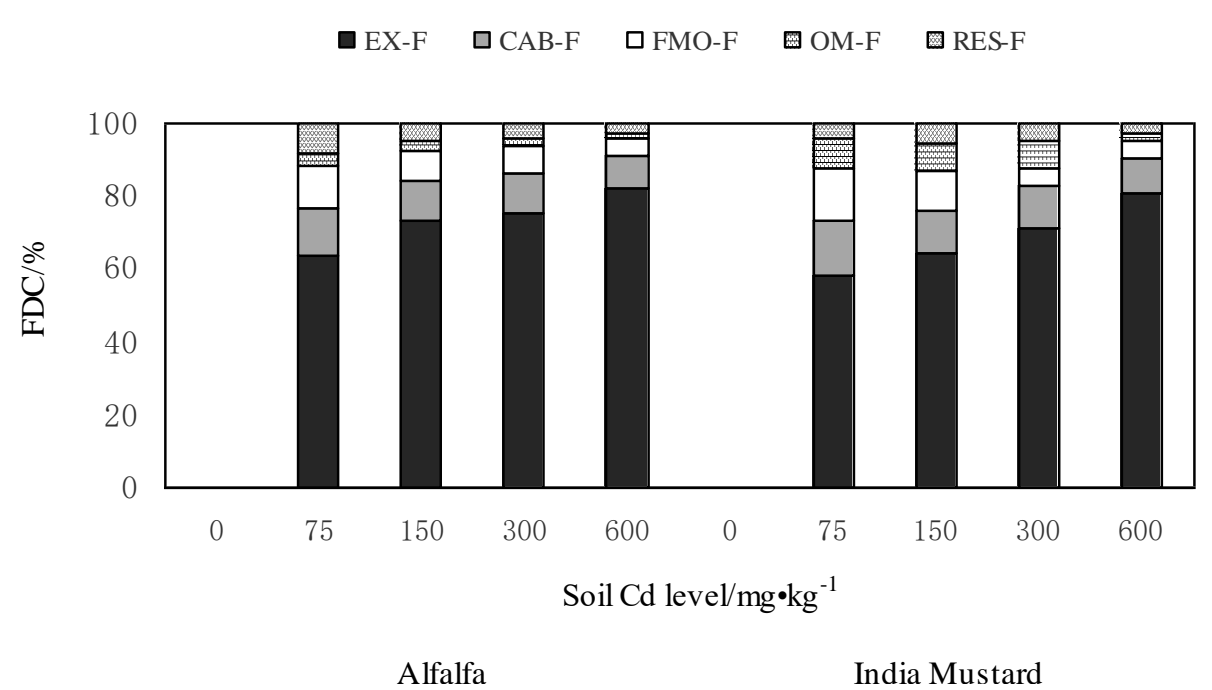

Figure 3. Effect of different soil Cd levels on Cd fraction distribution coefficient (FDC) in soils. Note: EX-F, CAB-F, FMO-F, OM-F and RES-F indicate Cd distribution coefficient (FDC) of exchangeable Cd, carbonate-bound Cd, Fe-Mn oxides-bound Cd, Organic Cd and residuals Cd in soil, respectively 
For Cd hyperaccumulator plants, Cd concentration in shoot should be 100 times higher than that of common plants (the critical value of $\mathrm{Cd}$ is $100 \mathrm{mg} \cdot \mathrm{kg}^{-1}$ ); $\mathrm{Cd}$ concentration of plant root should be lower that of shoot; the plant growth does not appear obvious toxicity symptoms and has strong resistance to $\mathrm{Cd}(\mathrm{Li}$ et al., 2017a; Lin and Feng, 2017; Sun and Song, 2015;). The results of this study showed that, Cd concentration in shoots of alfalfa and Indian mustard exceeded the $100 \mathrm{mg} \cdot \mathrm{kg}^{-1}$ threshold of hyperaccumulator plant at the $75 \mathrm{mg} \cdot \mathrm{kg}^{-1} \mathrm{Cd}$ level. This result was similar to that reported by Yang et al. (2011). In comparison of Cd concentration in shoots and roots of the two plants under the same soil $\mathrm{Cd}$ level, that of alfalfa > Indian mustard. However, in the analysis of biomass and $\mathrm{Cd}$ accumulation, the biomass of Indian mustard was much higher than that of alfalfa, therefore, its $\mathrm{Cd}$ accumulation was also significantly higher than that of alfalfa. Different plant organs have different levels of heavy metals (Li et al., 2017b). In this experiment, it was found that, for both alfalfa and Indian mustard, that in root > shoot at different soil Cd levels, and their roots had strong $\mathrm{Cd}$ enrichment ability, but their ability to transport $\mathrm{Cd}$ to shoots was weak. Similar results were reported by Chen et al. (2014), Jiao et al. (2014), Hattab et al. (2013), and Sun et al. (2016), but different from the report by Yang et al. (2011). In this experiment, with the increase of $\mathrm{Cd}$ concentration, $\mathrm{Cd}$ transport index of Indian mustard first increased and then decreased, while alfalfa $\mathrm{Cd}$ transport index also increased. This result was different from earlier reports (Li and Song, 2016). In addition, BCF of alfalfa and Indian mustard were above 1 when exposed to $\mathrm{Cd}$, while TF was lower than 1 . The higher root BCF value of Indian mustard suggests that Indian mustard has the strongest Cd enrichment ability.

It has been reported that there is a significant difference in soil $\mathrm{Cd}$ form among different crops (Zhang et al., 2017). In this experiment, EXC-Cd, CAB-Cd and FeMn$\mathrm{Cd}$ of alfalfa were significantly higher than that of Indian mustard under high concentration of Cd, while RES-Cd and OM-Cd were lower than that of Indian mustard, which was similar to the results of previous studies (Huang et al., 2000). It may be because different root exudates produced by different crops change $\mathrm{Cd}$ forms in the soil and mitigate $\mathrm{Cd}$ damage to the crop. In this experiment, the $\mathrm{Cd}$ in the two plants at different $\mathrm{Cd}$ levels both existed in the form of highly active EXC-Cd, and $\mathrm{Cd}$ concentration in different forms increased with the increase of $\mathrm{Cd}$ added concentration, which may be because $\mathrm{Cd}$ entered soil in the form of $\mathrm{Cd}$ solution with the highest activity (Xiong et al., 2015).

\section{Conclusion}

With the increase of soil Cd level, the biomass of shoots and roots of alfalfa and Indian mustard decreased significantly. The EXC-Cd was the dominating form of soil $\mathrm{Cd}$. With the increase of $\mathrm{Cd}$ level in soil, the percentage of EXC-Cd in total $\mathrm{Cd}$ also increased continuously. At 75 and $150 \mathrm{mg} \cdot \mathrm{kg}^{-1} \mathrm{Cd}$ levels, Cd concentrations in shoots of alfalfa and Indian mustard exceeded the critical value of hyperaccumulators, The BCFs of both alfalfa and Indian mustard were above 1. At the same soil Cd level, for BCF and TF values, those of Indian mustard > alfalfa. Based on comprehensive consideration of biomass, $\mathrm{Cd}$ accumulation, transport coefficient and enrichment coefficient, Indian mustard has stronger $\mathrm{Cd}$ accumulation ability, thus more suitable as repair material for soil Cd pollution. 
Acknowledgements. This work was supported by Fund of China Agriculture Research System (CARS23), the National Science and Technology Pillar Program of China (No. 2007BAD87B10), and Southwestern University Undergraduate Science and Technology Innovation "Guangjiong" Training Project (20150490).

\section{REFERENCES}

[1] Chen, Y. H., Liu, X. Y., Wang, M. X., Wan, Yan, X. M. (2014): Cadmium tolerance, accumulation and relationship with Cd subcellular distribution in Ricinus communis $\mathrm{L}$. Acta Scientiae Circumstantiae 9: 2440-2446.

[2] Feng, P., Sun, L., Shen, X. H., Jiang, C., Li, R. L., Li, Z. J., Zheng, H. Y., Zhang, H., Guo, W., Han, X. D., Hong, Y. N. (2016): Response and enrichment ability of perennial ryegrass under lead and cadmium stresses. - Acta Prataculturae Sinica 25(1): 153-162.

[3] Hattab, S., Hattab, S., Banni, M., Hernández, L. E., Boussetta, H. (2013): Modulation of antioxidant responses of Medicago sativa under cadmium and copper stress. - Afr. J. Agric. Res. 8(19): 2297-2306.

[4] Huang, Y., Chen, Y. J., Tao, S. (2000): Effect of rhizospheric environment of VAmycorrhizal plants on forms of $\mathrm{Cu}, \mathrm{Zn}, \mathrm{Pb}$ and $\mathrm{Cd}$ in polluted soil. - Chinese Journal of Applied Ecology 11(3): 431-435.

[5] Jiao, Y. N., Zhu, H. (2014): Physiological and morphological response of Sedum spectabile boreau under cadmium stress. - Acta Botanica Boreali-Occidentalia Sinica 34(6): 1173-1178.

[6] Kachenko, A. G., Singh, B. (2006): Heavy metals contamination in vegetables grown in urban and metal smelter contaminated sites in Australia. - Water, Air Soil Poll. 169: 10123.

[7] Li, N., Sun, N. X., Son, G. L., Pu, Y. X. H., Zhou, S. Q., Zhao, K. Q., Jiang, K. (2017a): Effects of cutting frequency on cadmium uptake and physiological responses of Medicago sativa under cadmium stress. - Acta Prataculturae Sinica 26(5): 109-117.

[8] Li, T., Xu, W. H., Chai, Y. R., Zhou, X. B., Wang, Z. Y., Xie, D. T. (2017b). Differences of $\mathrm{Cd}$ uptake and expression of Cd-tolerance related genes in two varieties of ryegrasses. - Bulgarian Chemical Communications 49(3): 697-705.

[9] Li, X. M., Song, G. L. (2016): Cadmium uptake and root morphological changes in Medicago sativa under cadmium. - Acta Prataculturae Sinica 25(2): 178-186.

[10] Lin, S. Y., Feng, Y. B. (2017): Study on phytoremediation of hyperaccumulators for cadmium, zinc and lead in the multiple contaminated soilds. - Environmental Engineering 35(3): 168-173.

[11] Liu, C. F., Shi, G. R., Yu, R. G., Zhang, Z. (2017): Eco-physiological mechanism of silicon-induced alleviation of cadmium toxicity in plants: A review. - Acta Ecologica Sinica 37(23): 1-12.

[12] Liu, S. L., Shi, X. S., Pan, Z. Y., Ding, J. H., He, Y., Wang, L. (2013): Effects of Cd stress on growth, biomass and nutrient accumulation and distribution of Catharanthus roseus. - Acta Prataculturae Sinica 22(3): 154-161.

[13] Lou, Y. H., Yang, Y., Hu, L. X., Liu, H. M., Xu, Q. G. (2015): Exogenous glycinebetaine alleviates the detrimental effect of Cd stress on perennial ryegrass. - Ecotoxicology 24: 1330-1340.

[14] Marzban, L., Akhzari, D., Ariapour, A., Mohammadparast, B. Pessarakli, M. (2017): Effects of cadmium stress on seedlings of various rangeland plant species (Avena fatua L., Lathyrus sativus L., and Lolium temulentum L.): Growth, physiological traits, and cadmium accumulation. - Journal of Plant Nutrition 40(15): 2127-2137.

[15] McCleod, S., (1975): Studies on Wet Oxidation Procedures for the Determination of Organic Carbon in Soil. - In: Notes on Soil Techniques, pp. 73-79. CSIRO Division of Soils, Melbourne, Australia. 
[16] Ning, X. P., Chen, W. Q. (2015): Development of remediation technology on soil polluted by cadmium. - Sichuan Chemical Industry 18(6): 18-20.

[17] Rayment, G. E., Higginson, F. R. (1992): Australian Laboratory Handbook of Soil and Water Chemical Methods. - Inkata Press, Melbourne, Australia.

[18] Sun, N. X., Song, G. L. (2015): Physiological response of Medicago sativa to cadmium stress and accumulation property. - Pratacultural Science 32(4): 581-585.

[19] Sun, Y. Y., Guan, P., He, S., Shi, J. M. (2016): Effects of Cd stress on Cd accumulation, physiological response and ultrastructure of Lolium multiflorum. - Pratacultural Science 33(8): 1589-1597.

[20] Tessier, A., Campbell, P. G. C., Bisson, M. (1979): Sequential extraction procedure for the speciation of particulate trace metals. - Analytical Chemistry 51(7): 844-851.

[21] Wei, S. H., Zhou, Q. X. (2004): Discussion on basic principles and strengthening measures for phytoremediation of soils contaminated by heavy metals. - Chinese Journal of Ecology 23(1): 65-72.

[22] Xiong, S. J., Xu, W. H., Xie, W. W., Chen, R., Chen, Y. Q., Ci, S. L., Chen, X. G., Zhang, J. Z, Xiong, Z. T., Wang, Z. Y., Xie, D. T. (2015): Effect of nano zeolite on chemical fractions of $\mathrm{Cd}$ in soil and its uptake by cabbage. - Environmental Science 36(12): 4630-4641.

[23] Yang, Z., Chen, J. Li, B. W. (2011): Effects of Cd contamination on number of microbes, physiological and biochemical characteristics of Brassica juncea. - Journal of AgroEnvironment Science 30(12): 2428-2433.

[24] Yu, P., Gao, F., Liu, J., Liang, Q., Han, Y. Y., Wang, J. X., Jia, Y. H. (2017): Effect of Cd on plant growth and its tolerance mechanism. - Chinese Agricultural Science Bulletin 33(11): 89-95.

[25] Zhang, L., Wu, L. K., Li, B,. ,Q., Wu, S., Wang, J. X. (2017): Research progress on difference of cd accumulating pattern and its mechanism among crop varieties. Northern Horticulture 2: 184-190. 